\title{
Investigation of Magnetic Pole Combination in a Surface Permanent Magnet-type Vernier Motor
}

\author{
Y. Kataoka, M. Takayama, Y. Matsushima*, and Y. Anazawa \\ Faculty of Systems Science and Technology, Akita Prefectural Univ., 84-4 Ebinokuchi, Yurihonjyo City, Akita 015-0055, Japan \\ * Faculty of Engineering, Shizuoka Univ., 3-5-1 Johoku Naka-ku, Hamamatsu City, Shizuoka 432-8561, Japan
}

A surface permanent magnet (SPM)-type vernier motor is a synchronous motor that generates large torque at a low speed. In the vernier motor, the number of slots, the pole of the rotating magnetic field on the armature, and the number of field poles on the rotor are constructed based on the vernier principle. In this paper, six magnetic pole combination types of these parameters are investigated by using a 36-slot stator, and the output characteristics, including the pull-out torque, are shown. These characteristics, calculated by torque and current equations, can be analyzed easily by investigating the induced electromotive force $E_{0}$ and the synchronous reactance $x_{\mathrm{s}}$. For the optimal design of the SPM-type vernier motor with a 36 -slot stator, it is clarified that one magnetic pole combination (S36-R68-P4, R/P:17) is effective for achieving a motor with high torque, and another magnetic pole combination (S36-R60-P12, R/P:5) is effective for achieving a motor with a high power factor.

Key words: vernier motor, surface permanent magnet, magnetic pole combination, torque equation, pull-out torque, voltage equation, power factor, zigzag leakage flux, harmonics

\section{Introduction}

Recently, drive systems requiring large torque at a low speed have become necessary for industrial machines, such as traction machines for elevators, servo press systems, and casting roll control systems for manufacturing film ${ }^{1}$. However, conventional drive systems, which are installed with mechanical reduction gears, have disadvantages such as backlash, mechanical loss, and maintenance. The direct drive system without reduction gears has been developed to eliminate these disadvantages. A vernier motor, which is a type of direct drive motor, generates large torque at a low speed and theoretically has no pulsating torque. Consequently, a suitable vernier motor for direct drive systems has been developed ${ }^{2)-4}$.

A surface permanent magnet (SPM)-type vernier motor is a synchronous motor installed in servo systems. To achieve high controllability and power factor in a direct drive machine, the torque must be increased and the power factor must be improved. Based on the vernier principle, several magnetic pole combinations can be designed in a multipolar SPM-type vernier motor if the motor volume and the number of slots are fixed uniformly. Hence, the effect of magnetic pole combinations needs to be evaluated to optimally design SPM-type vernier motors. Although Toba et al. ${ }^{5)}$ investigated a torque-maximizing design for an 18-slot stator using finite element analysis, the influence of the magnetic pole combination has yet to be adequately investigated experimentally and the calculation method is complicated. In this paper, six magnetic pole combinations of multipolar vernier motors with a 36 -slot stator, whose slots are increased further, are investigated using our proposed calculation method as well as voltage and torque equations. The output characteristics, including the pull-out torque, are analyzed intuitively by investigating the induced electromotive force $E_{0}$ and the synchronous reactance $x_{\mathrm{s}}$. The relation $S=R / 2+P / 2$ gives a large pull-out torque, where $S$ is the number of slots, $R$ is the number of field poles, and $P$ is the pole of the rotating magnetic field on the armature. The maximum pull-out torque is obtained as $R / P$ increases, but the maximum power factor is obtained as $R / P$ decreases.

\section{Magnetic pole combinations}

The vernier motor is a synchronous motor constructed based on the vernier principle and the relationship between the previously defined parameters $S, R$, and $P$, as shown in equation (1):

$$
S=\frac{R}{2} \pm \frac{P}{2} .
$$

Six magnetic pole combination types of vernier motors are investigated using a 36-slot stator. The specifications are shown in Table 1. The six combination types are selected except the two-pole machine, if the number of slots is fixed at 36 .

Fig. 1 shows the two-pole section of magnetic pole combination type A (S36-R60-P12, R/P:5). The stator has an ordinary three-phase armature winding. The number of slots per pole per phase $(q)$ is 1 , and this type generates 12 poles of the rotating magnetic field in the gap between the rotor and stator. The rotor has 60 magnetic poles $(R / P: 5)$. Therefore, the rotor rotates and synchronizes the 5th component of the rotating magnetic field, as shown in Fig. 2. The rotor speed is given in 
Table 1 Specifications of magnetic pole combination types.

\begin{tabular}{|c|c|c|c|c|c|c|c|c|}
\hline Items & & & A & B & $\mathrm{C}$ & $\overline{\mathrm{D}}$ & $\mathrm{E}$ & F \\
\hline Number of slots & $S$ & - & \multicolumn{6}{|c|}{36 (Fixed) } \\
\hline Number of field poles & $R$ & - & 60 & 84 & 66 & 78 & 68 & 76 \\
\hline Number of poles (Rotating magnetic field) & $P$ & - & \multicolumn{2}{|c|}{12} & \multicolumn{2}{|c|}{6} & \multicolumn{2}{|c|}{4} \\
\hline Number of field poles per pole & $R / P$ & - & 5 & 7 & 11 & 13 & 17 & 19 \\
\hline Operating voltage & $V$ & $\mathrm{~V}$ & \multicolumn{2}{|c|}{125} & \multicolumn{2}{|c|}{250} & \multicolumn{2}{|c|}{375} \\
\hline Operating frequency & $f$ & $\mathrm{~Hz}$ & \multicolumn{6}{|c|}{50 (Fixed) } \\
\hline Synchronous speed & $N$ & $\min ^{-1}$ & 100 & 71.4 & 90.9 & 76.9 & 88.2 & 78.9 \\
\hline Number of slots per pole per phase & $q$ & - & \multicolumn{2}{|c|}{1} & \multicolumn{2}{|c|}{2} & \multicolumn{2}{|c|}{3} \\
\hline Number of turns in an armature winding & $n_{\mathrm{c}}$ & Turn & \multicolumn{6}{|c|}{336 (Fixed, Full pitch) } \\
\hline Resistance of armature winding & $r_{\mathrm{a}}$ & $\Omega$ & \multicolumn{2}{|c|}{0.846} & \multicolumn{2}{|c|}{1.154} & \multicolumn{2}{|c|}{1.462} \\
\hline Core length & $l$ & $\mathrm{~mm}$ & \multicolumn{6}{|c|}{60} \\
\hline Core material & - & - & \multicolumn{6}{|c|}{$50 \mathrm{~A} 290$} \\
\hline Remanent flux density of magnet & $B_{\mathrm{r}}$ & $\mathrm{T}$ & \multicolumn{6}{|c|}{1.45} \\
\hline Coercive force of magnet & $H_{\mathrm{c}}$ & $\mathrm{kA} / \mathrm{m}$ & \multicolumn{6}{|c|}{1074} \\
\hline
\end{tabular}

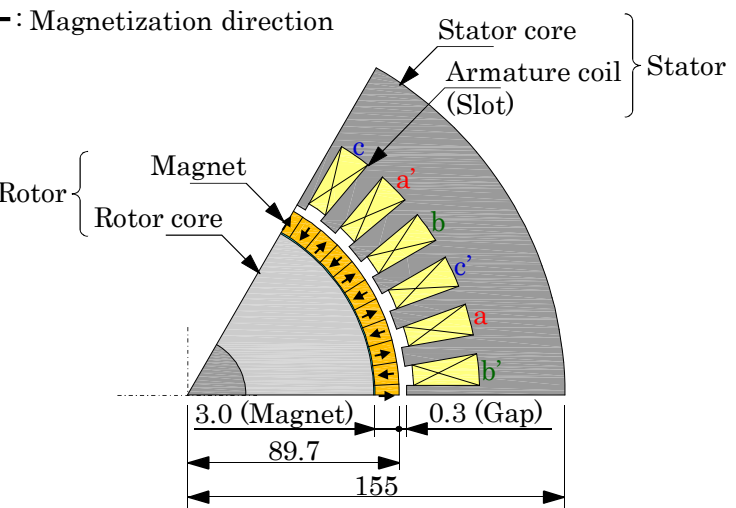

Fig. 1 Two-pole section of type A (Units: $\mathrm{mm}$ ) .

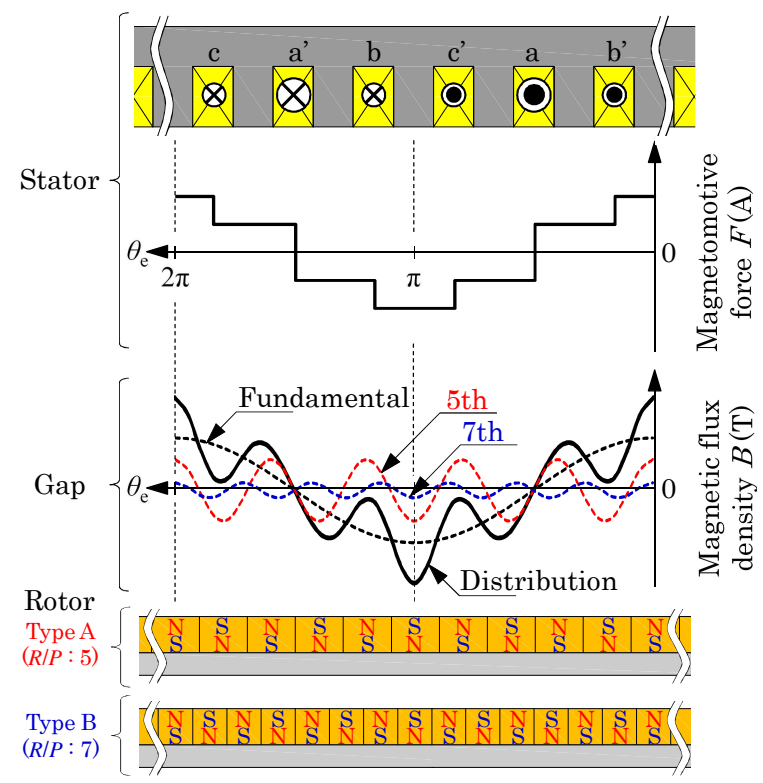

Fig. 2 Operation principle of types A and B. (Two-pole section) equation (2):

$$
N=\frac{120 f}{P} \cdot \frac{P}{R}=\frac{120 f}{R}
$$

where $N$ is the synchronous speed $\left(\mathrm{min}^{-1}\right)$ and $f$ is the power supply frequency $(\mathrm{Hz})$. In contrast, the type B rotor has 84 magnetic poles $(R / P: 7)$. Therefore, the rotor rotates and synchronizes the 7 th component. The operation principle is also shown in Fig. 2.

Fig. 3 shows the two-pole section of magnetic pole combination type $\mathrm{C}$ (S36-R66-P6, $R / P: 11)$. The number of slots per pole per phase $(q)$ is 2 . In this type, the armature winding generates 6 poles of the rotating magnetic field around the motor. The rotor has 66 magnetic poles $(R / P: 11)$; therefore, the rotor rotates and synchronizes the 11th component. Fig. 4 shows the two-pole section of magnetic pole combination type $\mathrm{E}$ (S36-R68-P4, $R / P: 17)$. The number of slots per pole per phase $(q)$ is 3 . The rotor has 68 magnetic poles $(R / P: 17)$; therefore, the rotor rotates and synchronizes the 17th component. The motor size of all types is fixed at the dimensions shown in Fig. 1.

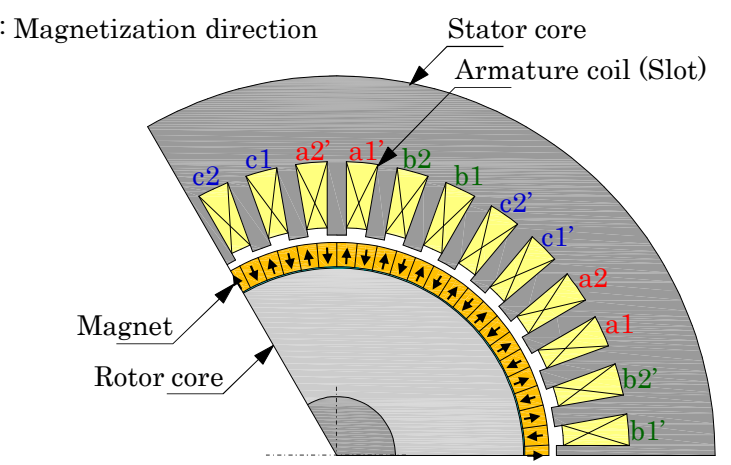

Fig. 3 Two-pole section of type C. 


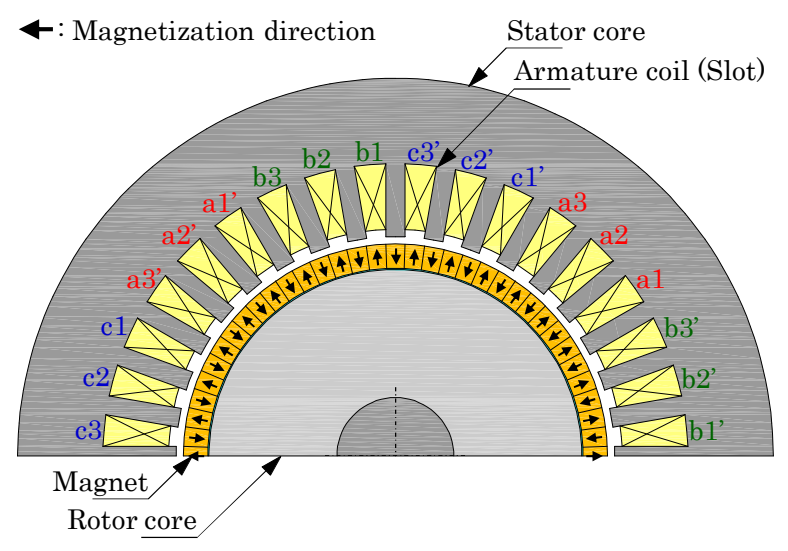

Fig. 4 Two-pole section of type E.

\section{Calculation method}

The torque equation is given in equation (3). The permanent magnet on the rotor is treated as an equivalent $\operatorname{coil}^{6)}$ :

$$
T=-\left(\frac{R}{2}\right) M_{\mathrm{F}} I_{\mathrm{F}} I_{\delta}
$$

where $T$ is the torque $(\mathrm{N}-\mathrm{m}), M_{\mathrm{F}} I_{\mathrm{F}}$ is the interlinkage magnetic flux $(\mathrm{Wb})$, and $I_{\delta}$ is the current on the $\delta$ axis (A) When balanced steady-state operation is considered, the voltage equations on the $\gamma-\delta$ axis of the SPM-type vernier motor are given in equations (4) and (5), and the induced electromotive force equation is given in equation (6) ${ }^{6}$ ):

$$
\begin{aligned}
& V \sin \left(\frac{R \delta_{\mathrm{L}}}{2}\right)=-r_{\mathrm{a}} I \sin \left(\varphi-\frac{R \delta_{\mathrm{L}}}{2}\right)+x_{\mathrm{s}} \cos \left(\varphi-\frac{R \delta_{\mathrm{L}}}{2}\right) \\
& V \cos \left(\frac{R \delta_{\mathrm{L}}}{2}\right)=x_{\mathrm{s}} \sin \left(\varphi-\frac{R \delta_{\mathrm{L}}}{2}\right)+r_{\mathrm{a}} I \cos \left(\varphi-\frac{R \delta_{\mathrm{L}}}{2}\right)+E_{0} \\
& E_{0}=\frac{\omega}{\sqrt{3}} M_{\mathrm{F}} I_{\mathrm{F}}
\end{aligned}
$$

where $V$ is the power supply voltage $(\mathrm{V}), r_{\mathrm{a}}$ is the resistance of the armature winding $(\Omega), x_{\mathrm{s}}$ is the synchronous reactance $(\Omega), \varphi$ is the power factor angle $(\mathrm{rad}), R \delta_{\mathrm{L}} / 2$ is the power angle (rad), $I$ is the armature current (A), $E_{0}$ is the induced electromotive force (V), and $\omega$ is the power supply angular frequency $(\mathrm{rad} / \mathrm{s})$.

The currents on the $\gamma$ and $\delta$ axis, given in equations (7) and (8), are obtained by transforming equations (4) and (5), respectively. The torque equation on the $\gamma-\delta$ axis is given in equation (9):

$$
\begin{aligned}
& I \sin \left(\varphi-\frac{R \delta_{\mathrm{L}}}{2}\right)=\frac{V}{Z} \sin \left(\varphi_{\mathrm{s}}-\frac{R \delta_{\mathrm{L}}}{2}\right)-\frac{E_{0}}{Z} \sin \varphi_{\mathrm{s}}=-\frac{I_{\gamma}}{\sqrt{3}}, \\
& I \cos \left(\varphi-\frac{R \delta_{\mathrm{L}}}{2}\right)=\frac{V}{Z} \cos \left(\varphi_{\mathrm{s}}-\frac{R \delta_{\mathrm{L}}}{2}\right)-\frac{E_{0}}{Z} \cos \varphi_{\mathrm{s}}=-\frac{I_{\delta}}{\sqrt{3}},
\end{aligned}
$$

$$
T=\frac{3}{\omega} \frac{R}{2}\left\{\frac{V E_{0}}{Z} \cos \left(\varphi_{\mathrm{s}}-\frac{R \delta_{\mathrm{L}}}{2}\right)-\frac{E_{0}^{2}}{Z} \cos \varphi_{\mathrm{s}}\right\},
$$

where $Z=\sqrt{r_{\mathrm{a}}^{2}+x_{\mathrm{s}}^{2}}, \varphi_{\mathrm{s}}=\tan ^{-1}\left(x_{\mathrm{s}} / r_{\mathrm{a}}\right)$, and $I_{\gamma}$ is the current on the $\gamma$ axis (A). The current and pull-out torque of the SPM-type vernier motor can be calculated by equations (7), (8) and (9), if the induced electromotive force $E_{0}$ and the synchronous reactance $x_{\mathrm{s}}$ are obtained. The output characteristics of the SPM-type vernier motor can be analyzed easily by using these two parameters. It is also found that the pull-out torque is proportional to $E_{0}$ and inversely proportional to $x_{\mathrm{s}}$. Therefore, it is clarified that the pull-out torque can be increased by the increase of $E_{0}$ and the decrease of $x_{\mathrm{s}}$.

Fig. 5 shows the flowchart for calculation of the pull-out torque and the current. In this investigation, $E_{0}$ and $x_{\mathrm{s}}$ are calculated by a finite element analysis (FEA: JMAG-studio, Ver. 10.0). In addition, leakage reactance $x_{1}$ is calculated by Kilgore's equation ${ }^{7)}$ and added to the reactance of the armature reaction $x_{\mathrm{a}}$, which is calculated by 2D FEA.

\section{Investigation of magnetic pole combinations}

\subsection{Pull-out torque}

The pull-out torque $T_{\mathrm{P}}$ are analyzed by calculating the induced electromotive force $E_{0}$ and the synchronous reactance $x_{\mathrm{s}}$. These are measured actually by a trial model of type A, and calculated value of type A ones are evaluated. Fig. 6 compares the induced electromotive force $E_{0}$. The calculated $(44.9 \mathrm{~V})$ and measured (39.2 V) values differ by $15 \%$. The induced electromotive force $E_{0}$ increases when the $R / P$ increases and the number of slots is determined by the equation $S=R / 2+P / 2$. Type $\mathrm{E}$ gives a large induced electromotive force $E_{0}$ of $80.7 \mathrm{~V}$.

Fig. 7 compares the synchronous reactance $x_{\mathrm{s}}$. The calculated $(5.40 \Omega)$ and measured $(5.96 \Omega)$ values differ by $9 \%$ for type A. The sychronous reactance increases as the number of slots per pole per phase $(q)$ increases. Fig. 8 compares the pull-out torque $T_{\mathrm{P}}$. The calculated (154 $\mathrm{N}-\mathrm{m})$ and measured (125 N-m) values differ by

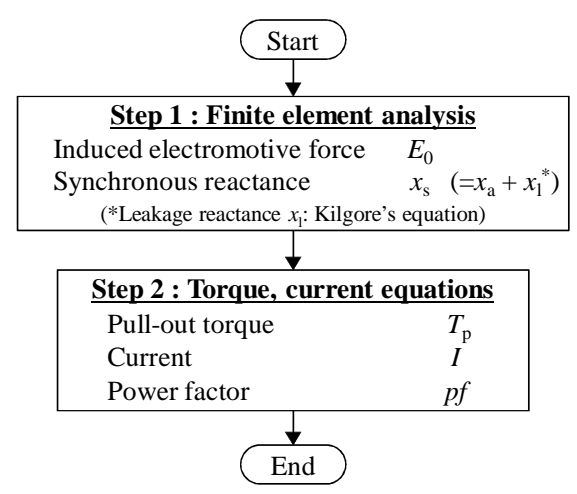

Fig. 5 Flowchart for calculation of the pull-out torque and the current. 


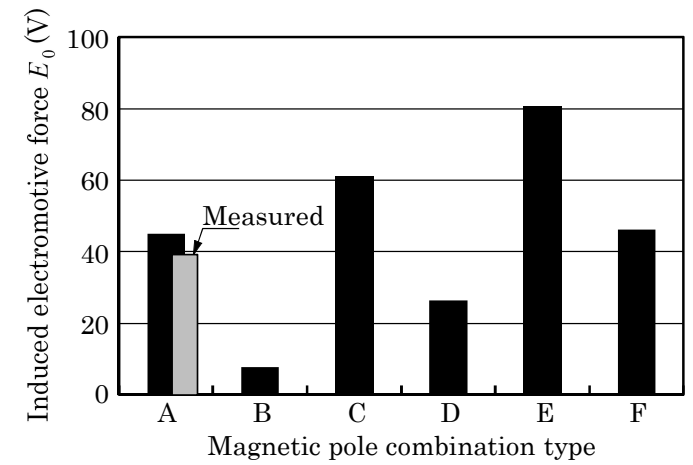

Fig. 6 Comparison of induced electromotive force.

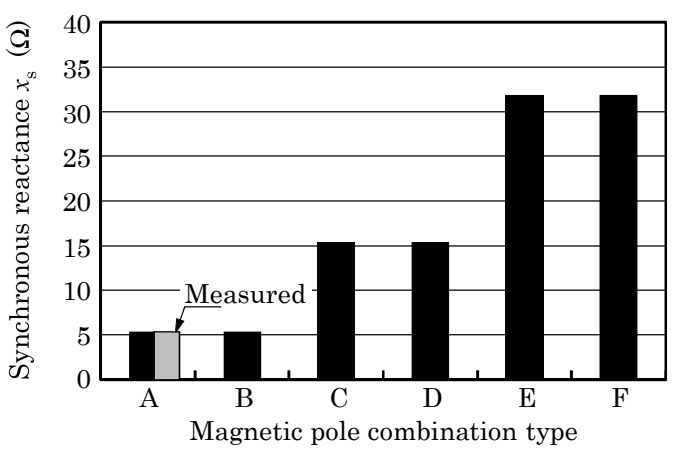

Fig. 7 Comparison of synchronous reactance.

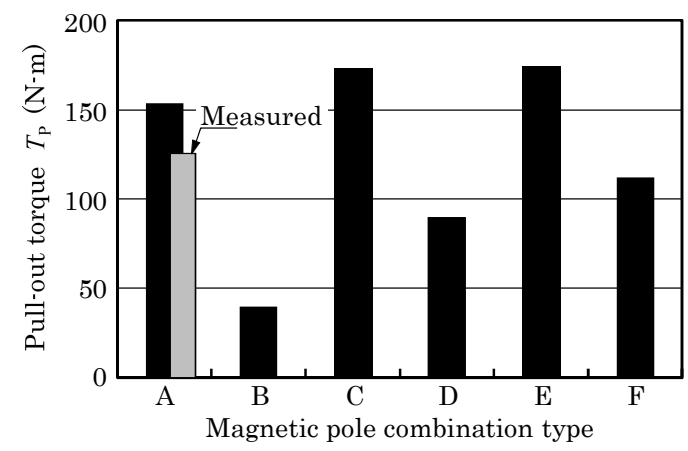

Fig. 8 Comparison of pull-out torque.
$23 \%$ for type A. The pull-out torque increases when the number of $R / P$ increases. Types $\mathrm{A}, \mathrm{C}$, and $\mathrm{E}$ have large pull-out torques because the number of slots is defined as $S=R / 2+P / 2$. Type E gives the maximum pull-out torque of $174 \mathrm{~N}-\mathrm{m}$ due to the large induced electromotive force $E_{0}$.

Fig. 9 shows the harmonics of the magnetic flux density distribution in the gap. The magnetic flux is modulated by the permeance wave; therefore, the fundamental component is obtained. Each type has the same order as the $R / P$ number. The magnitudes of these components are not changed by magnetic pole combination types. Fig. 10 shows the magnetic flux line of types A and B. The SPM-type vernier motor has a zigzag leakage flux, which passes the head of the teeth and leaks to the next magnet, and the magnetic flux of type $\mathrm{B}$ is large as compared with that of type A. Moreover, the surface area of the magnet of type $B$ is smaller than that of type A. Therefore, the induced electromotive force $E_{0}$ of type $\mathrm{A}$ is higher than that of type B. Similarly, type C and E constructed from the equation $S=R / 2+P / 2$ generate high $E_{0}$.

\subsection{Output characteristics}

Fig. 11 shows a comparison of the current. A large output of $1.6 \mathrm{~kW}$ is obtained by types A, C and E. Type E obtains a small current, because the synchronous reactance $x_{\mathrm{s}}$ becomes high. Fig. 12 shows a comparison of the power factor. The power factor increases as $R / P$ decreases according to the equation $S=R / 2+P / 2$. Type A $(\mathrm{S} 36-\mathrm{R} 60-\mathrm{P} 12, R / P: 5)$ gives a maximum power factor of $74 \%$. Therefore, decreasing $R / P$ can effectively achieve a motor with a high power factor.

\section{Conclusion}

Herein magnetic pole combinations of the SPM-type vernier motor are investigated for a 36-slot stator. Calculations using voltage and torque equations clarified output characteristics (pull-out torque, current, and power factor). The pull-out torque increases as $R / P$ increases. Hence, type E (S36-R68-P4, R/P:17) effectively realizes a high torque. On the other hand, the power

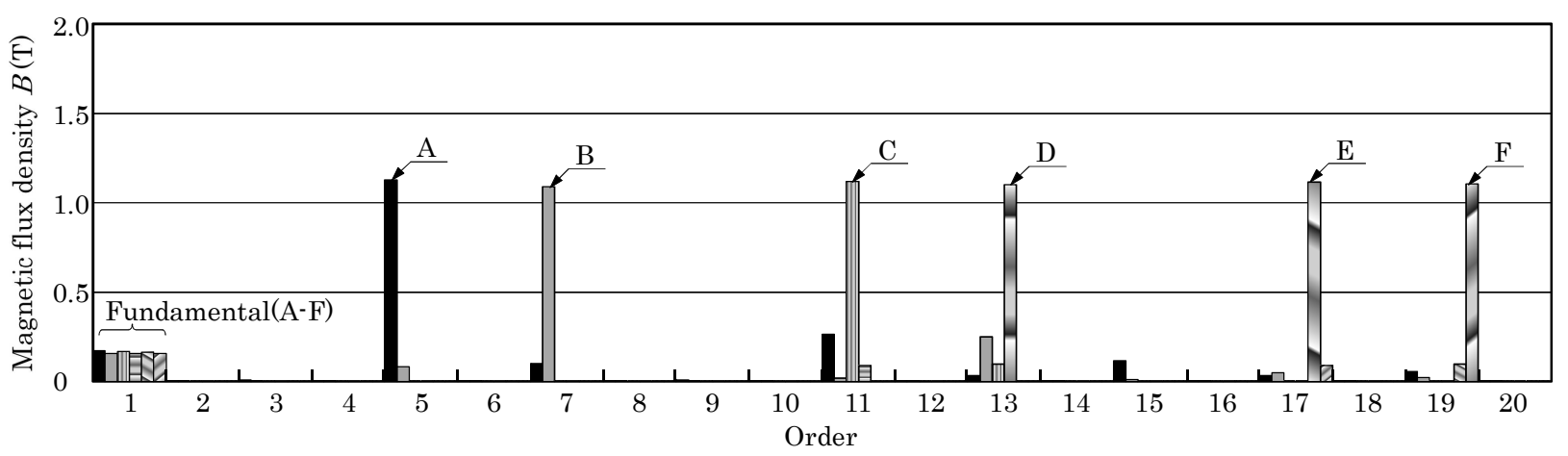

Fig. 9 Harmonics of magnetic flux density distribution in gap (Considering only magnetomotive force of magnet). 


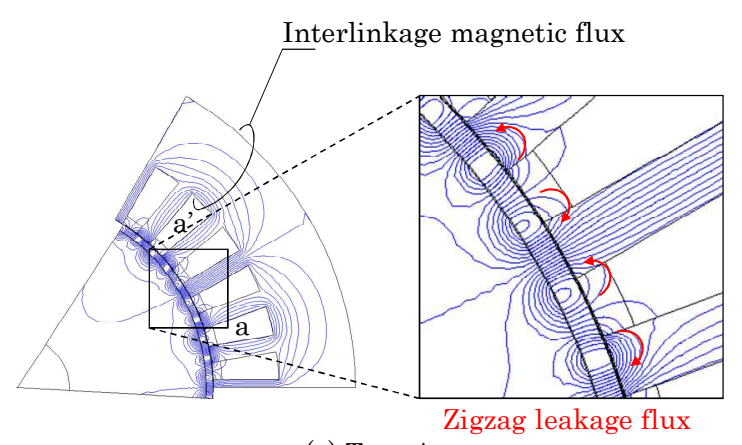

(a) Type A

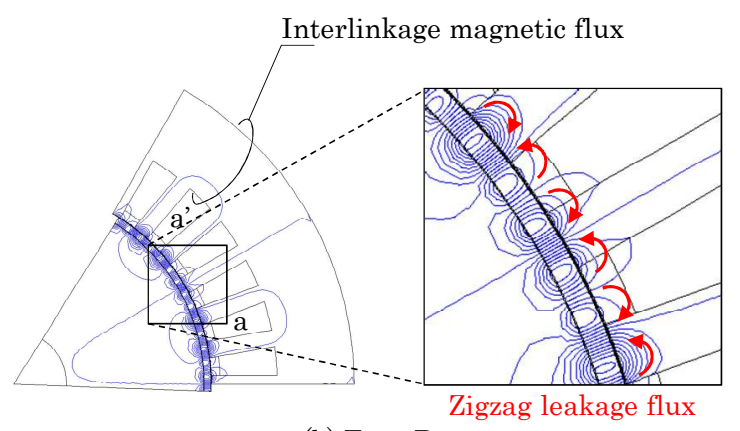

(b) Type B

Fig. 10 Types A and B magnetic flux lines.

factor increases as $R / P$ decreases, and type A (S36-R60-P12, R/P:5) achieves a high power factor. Additionally, the designs of types $\mathrm{A}, \mathrm{C}$, and $\mathrm{E}$ have practical applications because the pull-out torque and power factor of the magnetic pole combinations, which are constructed by $S=R / 2+P / 2$, are larger than those of types $\mathrm{B}, \mathrm{D}$, and $\mathrm{F}$, which are constructed by $S=R / 2-P / 2$. Consequently, this research clearly demonstrates that the design concept of a magnetic pole combination is applicable to optimal design.

In the future, the power factor for type $\mathrm{E}$ (S36-R68-P4, R/P:17) will be improved.

\section{References}

1) Y. Hojo, K. Akaike, K. Takahashi, and E. Anzai: Toyo denki review, 126, pp. 10-13 (2012).

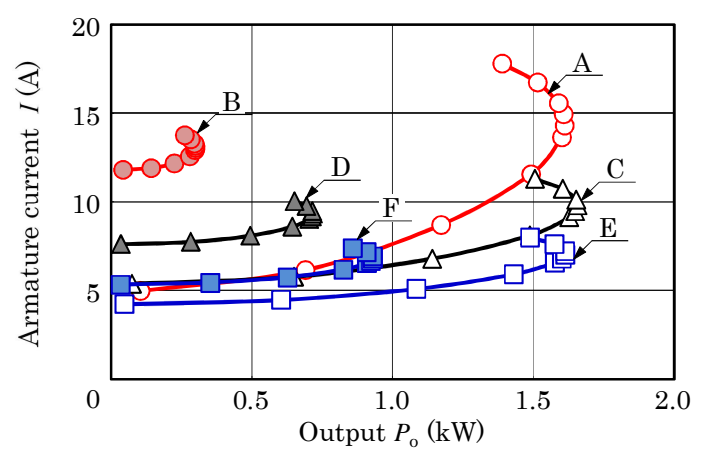

Fig. 11 Comparison of current.

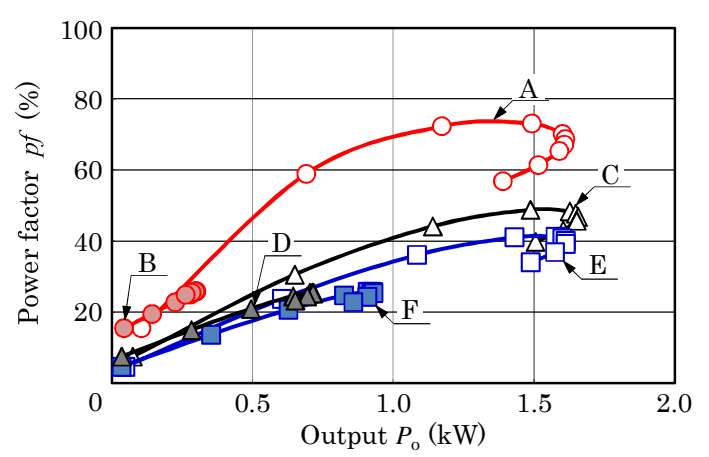

Fig. 12 Comparison of power factor.

2) A. Ishizaki, Y. Shibata, K. Watanabe, and K. Saitoh: T.IEE Japan, Vol. 111-D, No. 9, pp. 785-793 (1991).

3) A. Ishizaki, T. Tanaka, K. Takasaki, S. Nishizaki, K. Watanabe, and A. Katagiri: T.IEE Japan, Vol. 113-D, No. 10, pp. 1192-1199 (1993).

4) A. Toba, T. Watanabe, Y. Koganei, and H. Ohsawa: T.IEE Japan, Vol. 122-D, No. 2, pp. 162-168 (2002).

5) A. Toba and T. A. Lipo: IEEE Trans. IA., Vol. 36, No. 6, pp. 1539-1546 (2000).

6) H. Suda, Y. Matsushima, and Y. Anazawa: The papers of Technical Meeting on Rotating Machinery, IEE Japan, RM-07-33 (2007).

7) K. Hirose: Denki kiki sekkei (in Japanese), IEE Japan, p. 331 (1982).

Received October 19, 2012; Revised November 20, 2012; Accepted December 13, 2012 